\title{
O ENSINO NA EDUCAÇÃO SUPERIOR: UMA ANÁLISE DA METODOLOGIA “TREZENTOS” E SUA RELAÇÃO COM A PEDAGOGIA HISTÓRICO CRÍTICA
}

\author{
TEACHING IN HIGHER EDUCATION: AN ANALYSIS OF THE "THIRTY" METHODOLOGY \\ AND ITS RELATIONSHIP WITH HISTORICAL-CRITICAL PEDAGOGY \\ LA ENSEÑANZA EN LA EDUCACIONA SUPERIOR: UN ANÁLISIS DE LA METODOLOGÍA \\ “TREZENTOS” Y SUYA RELACIÓN COM LA PEDAGOGIA HISTÓRICO CRÍTICA
}

\section{Liliam Faria Porto Borge Vanice Schossler Sbardelotto}

RESUMO: O artigo apresenta uma análise da metodologia de ensino "Trezentos", desenvolvida pelo Professor Doutor Ricardo Ramos Fragelli, da UnB, desde 2013, no tange a relação existente entre essa metodologia de ensino empregada na Educação Superior e as pedagogias, aqui entendidas, como progressistas, particularmente a Pedagogia Histórico-Crítica, formulada e divulgada no Brasil por Dermeval Saviani. A metodologia ativa desenvolvida pelo Professor Fragelli se sustenta na admissão da possibilidade de aprendizagem de todos os estudantes e defende a necessária mediação docente para que esta ocorra de forma satisfatória, com isso, produzindo bons resultados de aprendizagem e aproveitamento destacado em área com recorrente fracasso dos estudantes na Educação Superior.

PAlavRAS-Chave: Metodologia "Trezentos". Pedagogia histórico-crítica. Aprendizagem. Ensino. Educação superior.

ABSTRACT: This paper analyzes the teaching methodology named as "The Three Hundred" developed by Professor Ricardo Ramos Fragelli, from the University of Brasilia (UnB), since 2013, concerning the existing synergy between this teaching methodology employed in higher education and progressive pedagogies, particularly the Historical-Critical Pedagogy formulated and published in Brazil by Dermeval Saviani. The active methodology developed by Professor Fragelli is based on assuring the learning possibility of all academics and supports the necessary teaching mediation so that such chance can occur in a satisfactory way and thereby produce good results on learning and improvement in higher education.

KEYWORDS: Methodology “The Three Hundred", Historical-critical pedagogy, Learning. Teaching. Higher education.

RESUMEN: La reseña presenta un análisis de la metodología de enseñanza "Trezentos", desarrollada por el Profesor Doctor Ricardo Ramos Fragelli, de la UnB, desde el año 2013, referente a la relación existente entre esta metodología de enseñanza empleada en la Educación Superior y las pedagogías, aquí entendidas, como progresistas, particularmente la Pedagogía Histórico-Crítica, formulada y divulgada en Brasil por Dermeval Saviani. La metodología activa desarrollada por el Profesor Fragelli se fundamenta en la admisión de la posibilidad de aprendizaje de todos los estudiantes y defiende la necesaria mediación docente para que esta ocurra de forma satisfactoria, y con esto, produciendo buenos resultados en el aprendizaje y aprovechamiento sobresalliente en el área con frecuente fracaso de los Estudiantes en Educación Superior.

Submetido em: 13/06/2017 - Aceito em: 10/07/2017 - Publicado em: 07/08/2017. 
PALABRAS CLAVE: Metodología "Trezentos". Pedagogía histórico-crítica. Aprendizaje. Enseñanza. Educación superior.

\section{INTRODUÇÃ̃}

O artigo busca apresentar uma reflexão sobre o necessário debate de apontamentos metodológicos para a docência na Educação Superior, a fim de levar a cabo o seu papel social: a formação integral humana.

As pedagogias progressistas, sobretudo, a Pedagogia Histórico-Crítica, a partir do seu fundamento teórico ancorado no materialismo histórico dialético de Marx e a psicologia histórico cultural de Vigostski e colaboradores, defende a necessidade de mediação pedagógica qualificada para que o processo de humanização, pela via da aquisição e apreensão de conceitos produzidos sobre o mundo natural e social, se torne eficaz.

A Educação Superior possui, entre outras, a função social de garantir a formação de graduados que possam, por meio de atividades de ensino, pesquisa e extensão, acessar os conhecimentos científicos, filosóficos e artísticos que lhes possibilite uma intervenção qualificada no mundo, como profissionais e cidadãos. Assim, a Universidade tem a preocupação de pesquisar, divulgar e socializar por meio de práticas de pesquisa e extensão estes conhecimentos, deve também ocupar-se de ensinar às novas gerações que adentram ao seu espaço aquilo que já se produziu coletiva e historicamente.

Este trabalho indica o ensino como um aspecto fragilizado do chamado tripé da universidade, sobretudo pelo massivo e necessário desenvolvimento da pesquisa com a verticalização das universidades. O que é, antes de mais nada, condição sine qua non para que se tenha efetivamente um espaço educativo com universalidade, a partir da produção dos conhecimentos.

Acerca da hipótese de uma fragilidade do ensino na Educação Superior, há que se tecer algumas considerações. É necessário que o ensino, em qualquer fase, considere seu interlocutor. De acordo com dados do Inep, $89 \%$ dos jovens que ingressam na educação superior são egressos do sistema público de ensino básico. Este nível de educação, no Brasil, nos últimos vinte anos voltou sua atenção ao desenvolvimento de competências e habilidades, conforme Duarte (2010). Tal situação implica que a apreensão de conceitos explicativos dos diferentes fenômenos pode ter sido secundarizada nas atividades escolares.

Os cursos de educação superior requerem o domínio das bases científicas do conhecimento, o que gera, no princípio do curso, o conflito entre o que se requer do estudante e o que fora ofertado a ele no processo educativo. Essa situação tem ocasionado diversos fenômenos 
observáveis nos mais diferentes cursos, como as sucessivas reprovações, abandono, evasão do curso e do sistema e, sobretudo, frustração e fracasso.

Essa condição se revela tanto no estudante quanto nos docentes e gestores, como a impossibilidade de realização do "sonho" da universidade por um lado e desânimo e até adoecimento dos docentes, por outro.

Essa problemática evidencia que todos os envolvidos, desde os docentes dos diferentes cursos, pedagogos, coordenadores de curso e estudantes devam se debruçar sobre essa importante questão, buscando travar um debate para promover a superação das dificuldades e qualificar o processo formativo. Um esforço teórico, pedagógico e administrativo para buscar possíveis respostas que objetivem atingir com eficácia a formação integral humana, afastando-se dos "negócios educacionais" que apresentam "kits" formativos genéricos, sem, por outro lado, desconsiderar a riqueza dos aparatos tecnológicos em benefício do ensino, como por exemplo, as tecnologias da informação.

Nesta perspectiva, destaca-se o amplo direito dos discentes acessarem os conhecimentos veiculados na Universidade e a plena capacidade humana de apreender novos conceitos, ainda que isso não se dê da mesma forma para todos. Conforme Leontiev (1978, p. 267), "todos os homens atuais [...] qualquer que seja a sua pertença étnica, possuem as disposições elaboradas no período de formação do homem e que permitem, quando reunidas as condições requeridas, a realização deste processo desconhecido no mundo dos animais", entende-se, que, buscar saídas metodológicas para o ensino na graduação deve ser preocupação e responsabilidade de todo docente. Pressupor que seu aluno seja capaz de aprender, ainda que isso lhe exija a revisão ou reorganização das formas pelas quais realiza o ato de ensinar. A metodologia "Trezentos" desenvolvida pelo Professor Ricardo Ramos Fragelli, é apresentada aqui como um exemplo didático da afirmação do ensino para que ocorra a aprendizagem, sendo esses dois elementos, polos de um único processo.

\section{A METODOLOGIA “TREZENTOS”}

A metodologia de ensino "Trezentos" foi desenvolvida pelo Professor Fragelli, desde 2013, sofrendo ajustes e melhorias desde então. O professor ministra a disciplina de cálculo em cursos de engenharia da UnB, disciplina marcada por uma tradição de reprovação e fracasso nos mais diversos cursos em diferentes instituições e não só no Brasil, mas o cálculo é, reconhecidamente uma disciplina desafiadora, quando não impeditiva da continuidade dos estudos. A metodologia aqui tratada tem sido aplicada desde 2013 e publicada na Revista Eletrônica Gestão \& Saúde em 2015, com o título "Trezentos: aprendizagem ativa e colaborativa como alternativa ao problema da ansiedade em provas". A proposta tem sido 
reconhecida nacionalmente e, inclusive recebeu o Prêmio Santander Universidades 2015 Categoria Apoio ao Aluno.

No texto de sua autoria, percebe-se que o Fragelli não detém grande preocupação na formulação de teorias explicativas sobre seu método, mas demonstra estar se movendo por um profundo respeito ao ser humano, seu interlocutor em sala aula: o estudante e o seu direito à aprendizagem.

Ao qualificar os dados observados no grupo de estudantes, percebeu que parte deles não lograva êxito na disciplina, sobretudo demonstrando desconforto no momento de verificação dos conhecimentos adquiridos. O professor atentou que grande parte dos estudantes não mantém uma relação positiva com a avaliação, de forma que este processo é extremamente traumático para boa parte deles, algo que faz parte do senso comum como natural, inclusive.

A partir desta constatação, passou a desenvolver diferentes práticas no momento da avaliação visando o sucesso dos seus estudantes. A melhora dos resultados foi visível.

Inspirado pela obra cinematográfica “300” (SNYDER, 2007), que por um enredo de guerra e fantasia, retrata a legião composta por trezentos espartanos liderada pelo Rei Leónidas contra o exército de mais de trezentos mil soldados persas, liderados pelo Rei Xerxes. A vinculação buscada pelo professor é a mensagem de trabalho em equipe e proteção solidária entre os membros de um mesmo grupo, e a ampliação das possibilidades de sucesso quando há cooperação. O professor Fragelli resolveu convidar seus estudantes para essa experiência em sala de aula. Criou uma organização metodológica que primou pelo envolvimento de todos os estudantes, inclusive aqueles que demonstravam os piores rendimentos na disciplina, e do professor.

(...) a metodologia dos Trezentos consiste em promover ao máximo a colaboração entre os estudantes, despertando o olhar para as dificuldades de aprendizagem do outro. Contudo, para que essa colaboração seja estimulada, são formados grupos de estudo de uma forma bem interessante. (FRAGELLI, 2015, p. 860)

A organização apresenta uma estrutura simples. Após a primeira avaliação, o professor "ranqueou" os alunos a partir da maior nota. Em seguida dividiu os alunos em subgrupos, com quatro estudantes cada, por ordem descrente de notas e, então reorganizou novos grupos com um membro de cada um dos grupos, integrando, portanto, alunos com os mais diferentes desempenhos. Com os novos grupos estruturados, discutiu metas de estudo coletivos para cada grupo e, após o cumprimento dessas metas, os estudantes que estavam abaixo da média na primeira avaliação, tiveram o direito de refazê-la.

Fragelli (2015) destaca que surgiram dúvidas ao longo do processo de como quantificar em nota o resultado do esforço de todos os membros do grupo heterogêneo, pois somente aqueles 
com nota inferior à média poderiam refazer a avaliação. Vale destacar que a tônica é a colaboração interna ao grupo, afinal na medida em que aquele que havia apreendido os conceitos compartilhava com aqueles estudantes que ainda guardavam dúvidas em relação ao conhecimento.

Com a criação da figura de linguagem de que todos "defendem" todos, os estudantes começaram a desenvolver uma postura mais sensível em relação ao outro, avaliando com maior generosidade as dúvidas dos colegas. A cada avaliação o professor refaz os grupos, considerando os resultados obtidos. Fragelli relata que em um dado semestre, oito das melhores médias ao final do período pertenciam a estudantes que figuravam entre as vinte piores médias na primeira avaliação.

Observa-se que a metodologia desenvolvida pelo professor Fragelli aposta na humanização dos sujeitos seja pela apropriação dos conceitos científicos, como pela formação ética e solidária que imprime nas suas aulas. Os resultados mostraram que

Em 58\% dos discursos apareceram termos que identificam a experiência da colaboração como sendo algo construtivo para o ser humano tais como "gratificante", "experiência única" e "ótima experiência", como neste caso: Ajudar e ser ajudado pelos colegas é uma experiência única. Uma dica ou outra sempre é bem-vinda de um colega ou para um colega, pois algo pode estar implícito durante um exercício. O 300 foi ótimo para mim, pois além de ajudar o outro, há uma parceria e um trabalho em equipe, o que não se vê com muita frequência em outras matérias. (FRAGELLI, 2015 p. 870)

A partir dos dados apresentados identificou-se que a possibilidade de apropriação de conteúdos superou, de forma absoluta, a média histórica que sempre foi próxima a $50 \%$ de aprovação na disciplina de Cálculo I, chegando, nesta primeira experiência a 85\%, conforme Fragelli (2015, p. 871)

\section{A PEDAgogia histórico-CRÍtica}

A experiência pedagógica do professor Fragelli nos remete a uma perspectiva pedagógica que considera os sujeitos envolvidos no processo de aprendizagem, tendo um claro e definido recorte de conteúdos e procedimentos metodológicos que ampliam a relação entre ensinar e aprender. Essa perspectiva nos permite uma aproximação analítica com a Pedagogia Histórico Crítica preconizada por Dermeval Saviani, nos anos de 1980, constitui-se como uma ferramenta teórica de organização do trabalho pedagógico em alternativa à pedagogia construtivista, hegemônica nas escolas nesse período.

Ao opor-se a pedagogia construtivista que, grosso modo, em seus fundamentos situa a ênfase do processo formativo na zona de interesses da criança, afirmando ser necessário reconstruir experiências para que ocorra a aprendizagem. Esta perspectiva entende ser mais importante

\begin{tabular}{l|c|c|c|c|c|} 
(C) Rev. Inter. Educ. Sup. & Campinas, SP & v.3 & n.3 & p.468-477 & set./dez. 2017 \\
\hline
\end{tabular}


desenvolver os meios de aprendizagem que a apreensão dos conceitos propriamente ditos, ou seja, todo a acento do processo se coloca na aprendizagem, descolando-a do ato de ensinar. A Pedagogia Histórico-Crítica reafirma a necessidade de apreensão, por parte dos aprendizes, dos conceitos mais elaborados e afirma que esta apreensão cumpre uma dupla função: no mesmo movimento que permite aos sujeitos desenvolver as ferramentas cognitivas para interpretar o mundo, também possibilita o desenvolvimento de novas aptidões, com a especialização das funções cognitivas superiores.

Desta forma, transmitir o conhecimento sobre o mundo natural e social acumulado historicamente às novas gerações, passa a ser o aspecto central desta pedagogia. A defesa desta postura pedagógica considera que a função social da escola - em qualquer nível - e, sobretudo, na educação superior, seja permitir que, todo ser humano, tenha como direito básico o acesso ao conjunto da riqueza humana expressa pelos conhecimentos em suas mais diversas dimensões. O pensamento científico e suas decorrências, assim com as artes e a filosofia.

Ou seja, a possibilidade de ampliarmos, de forma humana e democrática, aquilo que é herança de toda a humanidade - o conhecimento sobre o mundo - não pode negar a importância da transmissão pela escola dos conhecimentos mais desenvolvidos. Essa importância é destacada por Saviani (2005)

\footnotetext{
Os conteúdos são fundamentais e sem conteúdos relevantes, conteúdos significativos, a aprendizagem deixa de existir, ela transforma-se num arremedo, ela transforma-se numa farsa [...]. A prioridade de conteúdos é a única forma de lutar contra a farsa do ensino. Por que esses conteúdos são prioritários? Justamente porque o domínio da cultura constitui instrumento indispensável para a participação política das massas [...]. O dominado não se liberta se ele não vier a dominar aquilo que os dominantes dominam. Então, dominar o que os dominantes dominam é condição de libertação. (SAVIANI, 2005, p. 55)
}

Desta forma é tarefa da pedagogia, que é uma teoria da educação propositiva, que informa para a escola um determinado padrão de atividade, ocupar-se de identificar os conteúdos e as formas mais eficazes de garantir a apreensão destes conhecimentos.

Sendo assim a Pedagogia Histórico-Crítica constitui-se como uma proposição para as atividades escolares que surge da crítica às pedagogias hegemônicas - Tradicional, Nova e Tecnicista. Estas pedagogias são chamadas por Saviani de pedagogias não críticas, porque não tem como finalidade desvelar o real, mas propõem-se a ajustar o sujeito ao meio de forma submissa e sem autonomia.

Para Saviani (2012), a Pedagogia Histórico-Crítica é, portanto, uma pedagogia concreta, que "considera que os educandos, enquanto indivíduos concretos, manifestam-se como unidade 
da diversidade, 'uma rica totalidade de determinações e de relações numerosas', síntese de relações sociais" (SAVIANI, 2012, p. 79).

A Pedagogia Histórico-Crítica, orienta uma determinada forma de compreensão do conhecimento, do papel social da escola, da função do professor e do aluno no processo de ensino e aprendizagem. Facci (2004), nos informa, em seus estudos, como a perspectiva da Psicologia Vigotskiana, ou histórico cultural, articulada em essência à Pedagogia HistóricoCrítica, orienta o trabalho do professor deve se dirigir ao mesmo tempo para o desenvolvimento filogenético e ontogenético.

Entende-se, a partir desta tradição do pensamento pedagógico e dos autores aqui citados, o desenvolvimento filogenético como formação das funções psicológicas superiores (memória ativa, atenção voluntária, pensamento abstrato, planejamento) e o desenvolvimento ontogenético como a formação de conceitos científicos que exige, necessariamente, a valorização da intervenção do sujeito mais maduro no processo de aquisição do conhecimento de um sujeito que ainda não teve a apropriação dos conteúdos em questão.

Para Leontiev (1978) as faculdades psíquicas do homem são resultado da aquisição dos bens materiais e culturais produzidos filogeneticamente. A apropriação dos conceitos modifica as atividades das funções psíquicas e cria novos níveis de desenvolvimento. Esse processo ocorre pela mediação dos signos - que são artifícios criados pelo homem que potencializam suas capacidades.

As funções psicológicas superiores estruturam-se na transição para a adolescência (na criança percebe-se mais memória, menos abstração, na adolescência isso se inverte). $O$ desenvolvimento das funções psicológicas superiores está estreitamente ligado à escolarização, visto que são elas que permitem o pensamento por conceito. Estes conceitos, possíveis pela utilização de signos podem ser do tipo espontâneo e científico.

Os primeiros são resultantes da experiência direta, enquanto os segundos são assimilados com ajuda do professor, sujeito que domina o conhecimento. $\mathrm{O}$ desenvolvimento dos conceitos científicos apoia-se nos conceitos espontâneos.

O processo de educação formal escolarizado tem a função de promover a aprendizagem dos conceitos do tipo científico, produzir no indivíduo singular o resultado da humanização, e pela via da aquisição dos produtos culturais ascender a autonomia de pensamento. Esse caminho - recorrentemente interditado em disciplinas de cálculo, nos mais diferentes cursos e instituições - vem se constituindo por meio de um procedimento metodológico que carrega, segundo a análise aqui defendida, os fundamentos da Pedagogia Histórico Crítica. 


\section{A METOdOLOgia DE ENSINO “TREZENTOS” E A PEDAgOgia hISTÓRICO- CRÍTICA}

O desenvolvimento de ações metodológicas em sala de aula evidencia uma correlata teoria educacional, ainda que ela, em alguns casos, não esteja presente à consciência do professor. Assim, observa-se alguns professores afirmarem que abstraem das diferentes correntes pedagógicas o que lhe interessa para dirigirem sua atividade docente. Esta possibilidade nos parece estranha, visto que, muitas vezes, o referencial teórico das diferentes pedagogias se mostra antagônicos, logo, não seria possível que estes diferentes elementos apresentassem uma unidade. O resultado destas posturas tem ocasionado um esvaziamento de sentido e significado da ação docente e da compreensão, pelos estudantes, da relação entre os conteúdos escolares e o mundo concreto.

A metodologia em questão evidencia uma metodologia ativa e colaborativa de aprendizagem, que requer a ação dos estudantes no seu processo de aprendizagem. Poderia, por este aspecto ser vinculada à pedagogia construtivista. Entretanto, o objetivo do trabalho pedagógico não se expressa pela forma, e sim pelo fim que pretende alcançar.

Ao afirmar que esta metodologia guarda vínculo com a Pedagogia Histórico-Crítica enfatizase que diversificadas formas de organização do trabalho pedagógico podem ser empregadas para a consecução do papel social da escola, que, de acordo com esta pedagogia, o que é central, efetivamente é a difusão entre as novas gerações do legal cultural humano.

No entanto, a disposição de buscar os mais diversos procedimentos metodológicos não elimina e ao contrário, fortalece, o objetivo central - qual seja - garantir a aprendizagem de um conjunto de conceitos que são basilares e fundamentais para a formação dos estudantes. Pode-se identificar, a partir desta questão central, ainda outros aspectos que podem ser depreendidos da metodologia "Trezentos" que se alinham aos objetivos da Pedagogia Histórico-Crítica.

O reconhecimento das potencialidade humanas de aprendizagem presentes em todos os seres humanos; a ênfase na ciência como produto cultural humano que pode ser apreendido por todos; a afirmação da responsabilidade do docente na condução do processo de ensino e aprendizagem, como sujeito que domina a conteúdo e a forma; a dialogicidade como ferramenta para aprendizagem; o reconhecimento da zona de desenvolvimento próximo, que permite compreender que os conceitos a serem aprendidos devem se articular a outros já dominados pelos estudantes; a afirmação da mediação pelos signos como forma mais apropriada para garantir a aprendizagem. Por fim, o insubstituível compromisso ético com a socialização do conhecimento como um bem público e direito individual. 
Ainda que não haja uma deliberada filiação do professor à perspectiva aqui indicada, a possibilidade de vinculação se apresenta na medida em que a garantia da apropriação de fundamentos matemáticos são condição orientadora de todo o trabalho pedagógico, alimentado pelo pressuposto que todos os alunos têm a capacidade de apropriação, ainda que em tempos e por meios diferenciados. O exercício docente indica a disposição de encontrar os meios e os procedimentos metodológicos necessários e adequados aos diferentes sujeitos para que, efetivamente, os conteúdos sejam apropriados. Considerando que tais conteúdos, na disciplina de cálculo, são fundamento de estudos sequentes, entendemos que a contribuição dada por este caminho pedagógico se revele alavancador de apropriações outras, mais complexas e elaboradas.

\section{CONCLUSÃO}

Ao apontar esses elementos que permitem estabelecer uma análise da metodologia "Trezentos" a partir da Pedagogia Histórico-Crítica, ousa-se afirmar de que diferentes formas podem abrigar os objetivos humanos e sociais com o ensino de conceitos científicos defendidos por essa pedagogia.

Tal como esta inovação metodológica que apostou na capacidade de aprendizagem e na consciência do ato de ensinar, aliados à solidariedade entre os estudantes, outras ferramentas e artefatos sociais podem ser utilizados a partir dos referenciais teóricos da Pedagogia Histórico-Crítica, especialmente aos da tecnologia da informação.

Com isso, defende-se que, ao lançar mão das ferramentas produzidas socialmente, ainda que sob égide do capital, pode se fazer uso destas em prol do desenvolvimento de novas potencialidades humanas, com vistas a avançar cada vez mais e mais na humanização de todos.

Assinala-se que esta metodologia, inspirada em uma obra cinematográfica, é exemplar do movimento reflexivo docente para o planejamento de práticas pedagógicas a partir das necessidades existentes em sala. E, ao passo que se destaca a positividade da sua difusão, enquanto uma possibilidade de adesão de outros professores a esta metodologia, ela torna-se positiva também por expor a versatilidade que a sala de aula exige dos docentes e encoraja colegas a ousarem também, apostando sempre na capacidade cognitiva que pertence a todos os seres humanos.

Desta forma, a exemplificação aqui exposta elucida a abrangência de diálogos que pedagogia histórico-crítica pode estabelecer na busca infindável por melhores métodos que garantam a apreensão dos conceitos por parte dos estudantes. Isso demarca a importância do binômio conteúdo e forma que se constitui como tarefa do exercício da docência, tão importante

\begin{tabular}{|l|l|l|l|l|l|} 
(c) Rev. Inter. Educ. Sup. & Campinas, SP & v.3 & n.3 & p.468-477 & set./dez. 2017 \\
\hline
\end{tabular}


quanto é conhecer os conteúdos que se quer lecionar, é investigar e conhecer as formas mais adequadas para desenvolver a mediação, a sua transmissão.

\section{REFERÊNCIAS}

DUARTE, Newton. O debate contemporâneo das teorias pedagógicas. In: MARTINS, Lígia Márcia, DUARTE, Newton (Org). Formação de professores: limites contemporâneos e alternativas necessárias. São Paulo: Cultura Acadêmica, 2010. 192 p.

FACCI, Marilda Gonçalvez Dias. Valorização ou esvaziamento do trabalho do professor? um estudo crítico-comparativo da teoria do professor reflexivo, do construtivismo e da psicologia vigotskiana. Campinas, SP: Autores Associados, 2004. 292 p.

FRAGELLI, Ricardo Ramos. Trezentos: aprendizagem ativa e colaborativa como uma alternativa aos problemas da ansiedade em provas. Revista Eletrônica Gestão \& Saúde. v. 6, Supl. 2, p.860-872, abr. 2015. Disponivel em: <http://periodicos.unb.br/index.php/ rgs/article/view/22605/16154>. Acesso em: 27 fev.2017.

LEONTIEV. Alexis. O desenvolvimento do psiquismo. Lisboa: Livros Horizontes, 1978. $352 \mathrm{p}$.

SAVIANI, Dermeval. Escola e democracia: teorias da educação, curvatura da vara, onze teses sobre a educação política. 37. ed. Campinas, SP: Autores Associados, 2005. 112p.

SAVIANI, Dermeval. DUARTE, Newton. (Org.). Pedagogia histórico-crítica e luta de classes na educação escolar. Campinas, SP: Autores Associados, 2012. 184p.

300. Dir. Zack Snyder. Prod. Mark Canton, Bernie Goldman, Gianni Nunnari e Jeffrey Silver. EUA, 2007. DVD (117 min).

\section{${ }^{\mathrm{i}}$ Sobre as autoras}

\section{Liliam Faria Porto Borges}

E-mail: liliamfpb@gmail.com / ORCID: http://orcid.org/0000-0001-6971-1802

Universidade Estadual do Oeste do Paraná - Brasil

Doutora em Educação pela Universidade Estadual do Oeste do Paraná [UNIOESTE].

\section{Vanice Schossler Sbardelotto}

E-mail: vanice.sbar@gmail.com / ORCID: http://orcid.org/0000-0003-4551-768X

Universidade Estadual do Oeste do Paraná - Brasil

Doutoranda em Geografia pela Universidade Estadual do Oeste do Paraná [UNIOESTE]. 